\title{
Transport Behavior in Polymer-Inorganic Membrane: A Review
}

\author{
N. N. Nik Mustofara,b, Juhana Jaafar ${ }^{a^{*}}$, M. Aziz ${ }^{\mathrm{b}}$, A. F. Ismail ${ }^{\mathrm{a}}$, Mukhlis A. \\ Rahman $^{\text {a }}$, M. H. D. Othman ${ }^{\text {a }}$, N. Yusof ${ }^{a}$, W. N. W. Salleh ${ }^{\text {a }}$ F. Aziz ${ }^{\text {a M. S. Rosmic,d }}$ \\ aAdvanced Membrane Technology Research Centre (AMTEC), \\ Universiti Teknologi Malaysia, 81310 UTM Johor Bahru, Johor, Malaysia \\ ${ }^{b}$ Department of Chemistry, Faculty of Science, \\ Universiti Teknologi Malaysia, 81310 UTM Johor Bahru, Johor, Malaysia \\ ${ }^{c}$ Department of Chemistry, Faculty of Science and Mathematics, Universiti \\ Pendidikan Sultan Idris, 35900 Tanjung Malim, Perak, Malaysia \\ ${ }^{\mathrm{d}}$ Department of Frontier Material, Graduate School of Engineering, Nagoya Institute \\ of Technology, Nagoya, Japan
}

\begin{abstract}
The polymer-inorganic composite membrane has emerged as an alternative to improve the separation properties of polymer membranes because they possess properties of both organic and inorganic membranes such as good hydrophilicity, selectivity, permeability, mechanical strength, and thermal and chemical stability. A unique combination of organic and inorganic properties is believed could overcome the limitations of the pure polymeric membranes. Transport behavior of gases, vapours and liquids through polymer membranes are important in ultrafiltration, nanofiltration, pervaporation, gas separation and fuel cell applications. A better understanding of transport mechanisms in polymer-inorganic composite membranes is highly important in order to achieve significant achievement in the respective applications. This article provides a detailed review of current research in the field of transport phenomena on the transport behaviour of proton and methanol through the polymeric-inorganic by means of proton conductivity and methanol permeability.
\end{abstract}

Keywords: Polymer-inorganic membranes, transport mechanism, proton transport, methanol transport, ion exchange membrane

\subsection{INTRODUCTION}

During the past decade, fuel cells have received much attention all over the world as novel electrical energy conversion systems. The higher efficiencies and lower emissions make the fuel cells a valuable contribution to the power generation facilities [1]. A fuel cell is a technology that converted the energy of a fuel directly into electricity direct current (DC) by an electrochemical reaction without resorting to a burning process, rather than to heat by a combustion reaction [2]. Fuel cells are considered to be the key technology for power generation in stationary, automotive, portable and even micro-scale systems [3].

The development of the direct methanol fuel cell (DMFC), a galvanic electrochemical flow system which converts directly chemical energy to electrical energy fuel has gained much interest in recent years. It uses methanol as a fuel which considered to be the promising technology for clean and efficient power generation since they offer numerous potential benefits, such as high efficiency, high power density, low or zero emissions and reliability [4-6]. It was first 
investigated in 1950's and the research on these systems received much attention in 1990's with the use of Nafion [7]. This type of fuel cell was found to be an alternative energy generator for transportation and portable application due to its simplicity and compact design. In addition, it is without fuel processing unit and convenient storage [8]. Several organizations are actively engaged in the development of lower power DMFCs for cellular phone, laptop computer, portable camera and electronic game applications [9-11].

Proton exchange membrane (PEM) acts as important key component in fuel cell system. It functions as an electrolyte for transferring protons from anode to cathode and also as a separator to prevent the mixing of fuel [12]. For a PEM to be useful in DMFCs, it should be sufficiently high in proton conductivity, significantly low methanol permeability, good electrical insulation, high mechanical and thermal stability, good oxidative and hydrolytic stability, low swelling stress, low cost and flexibility to be fabricated as membrane electrode assembly (MEA) [13]. Sulfonated polyether ether ketone (SPEEK) has been studied as polymer electrolyte membrane for DMFC applications due to its low cost, high conductivities, excellent mechanical and thermal properties. Sulfonation process enhances the PEEK acidity and hydrophilicity as the presence of water able to facilitate proton transfer and increases the conductivities. When the degree of sulfonation increases, the water uptake and proton conductivity increases. Unfortunately, the methanol permeability also increases and thus affected the efficiency of the membranes. Therefore, the increasing of methanol permeability in SPEEK membrane leads to the study of modification of SPEEK membrane among the researchers. The studies regarding the development of polymerinorganic composite membranes have been widely reported. The fabrication of composite membranes of SPEEK with silicon oxide $\left(\mathrm{SiO}_{2}\right)$, titanium oxide $\left(\mathrm{TiO}_{2}\right)$, zirconium oxide $\left(\mathrm{ZrO}_{2}\right)$ and layered silicate materials have been reported to have reduced swelling without any appreciable reduction in conductivity [14-15]. The fabrication of SPEEK/montmorillonite clay nanocomposite membranes with low methanol permeability but sacrifices the proton conductivity at higher loading as compared to Nafion 117 was also reported [16]. Based on the previous findings, the trend of proton conductivity and methanol permeability results in polymerinorganic membrane is either enhance $[14,15,17]$ in both or significantly reduced [16, 18, 19] in both characteristics. However, interestingly some findings reported that the introduction of inorganic materials in polymer matrix has successfully reduced methanol permeability without sacrificing the proton conductivity. It even improved as compared to parent polymeric membrane [20]. Therefore, it is crucial to deeply understand the factors affecting the methanol and proton transport via polymer-inorganic membrane. Since the literature information in this topic is scarce, this present paper provides a review on the transport behaviour of proton and methanol through the polymericinorganic by means of proton conductivity and methanol permeability.

\subsection{TRANSPORT MECHANISM IN MEMBRANE}

The transport phenomena can be described with two mechanisms that are solution-diffusion and pore-flow 
models. In solution-diffusion model, the permeants is dissolved in the membrane material and then diffuse through the membrane down a concentration gradient. A separation is achieved when the permeants are separated because of the differences in the solubility of the materials in the membrane and the differences in the rates at which the materials diffuse through the membrane [21]. This solution-diffusion mechanism is mostly used in the mass transport of non-porous membrane for reverse osmosis, pervaporation and gas separation applications [22].

On the other hand, the pore-flow model assumed that the solvent and solute concentrations within a membrane are uniform and the chemical potential gradient across the membrane is expressed only as a pressure gradient [21]. Permeants are separated by pressure-driven convective flow through tiny pores. A separation is achieved between different permeants because one of the permeants is filtered from some of the pores in the membrane through which other permeants move [23]. For the pure solvent, the permeant flux is directly proportional to the pressure gradients across the membrane [24]. Figure 1 illustrates the difference between the solution-diffusion and pore-flow mechanisms.

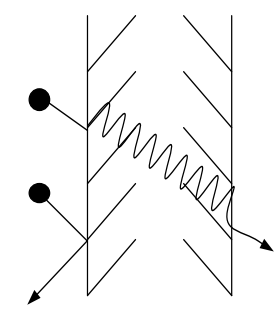

Solution-diffusion model

Figure 1 Transport mechanism model in membranes
The relative size and permeance of the pores indicates the differences between the pore flow and solution-diffusion mechanisms. For membranes in which transport is best described by the solution diffusion model and Fick's law, the free volume elements in the membranes are tiny spaces between polymer chains caused by thermal motion of the polymer molecules [21]. On the other hand, for a membrane in which transport is best described by a pore-flow model and Darcy's law, the free volume elements relatively large and fixed, do not fluctuate in position or volume on the scale of permeant motion and are connected to one another [21].

\subsection{TRANSPORT MECHANISM IN ION EXCHANGE MEMBRANE}

The presence of fixed charge affects the mass transport of ions in ion exchange membrane. There are two different types of ion exchange membrane. They are cation exchange membrane and anion exchange membrane which contain fixed negative and positive charges, respectively. The interactions between ionic species in solution and the fixed charges in the ion exchange material occurs when the fixed charges absorb counter-ions and repels the co-ions during the ion exchange materials are in contact with ionic species. The coions in solution attract the counter-ions back into the solution in order to maintain charge naturally. This phenomenon is known as the Donnan effect [25].

Water plays a significant role in the transportation of proton in hydrophilic domains of polymeric membranes as it facilitates the migration of proton through the membrane. From previous research, it was reported that the water absorbed in the membrane can be 
classified into two types which are bound and free water. The bound water is the water that strongly bound to the ionic groups of the copolymer while the water that has the same thermal transitions as bulk water that can be frozen at normal temperature is known as free water. The proton transports in hydrated polymeric matrices is in general described on the basis of either of the two principal mechanisms that are free solution diffusion process (vehicle mechanism) and proton hopping (Grotthus mechanism). The simple scheme of free solution diffusion and Grotthuss mechanism has been shown in Figure 2.

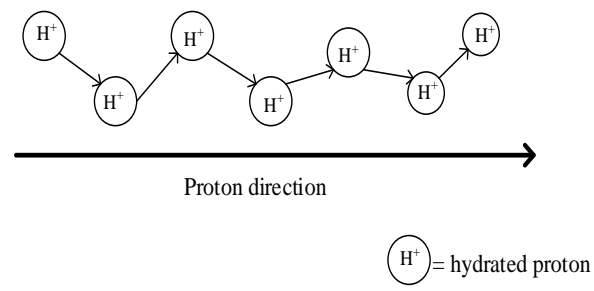

Free solution diffusion

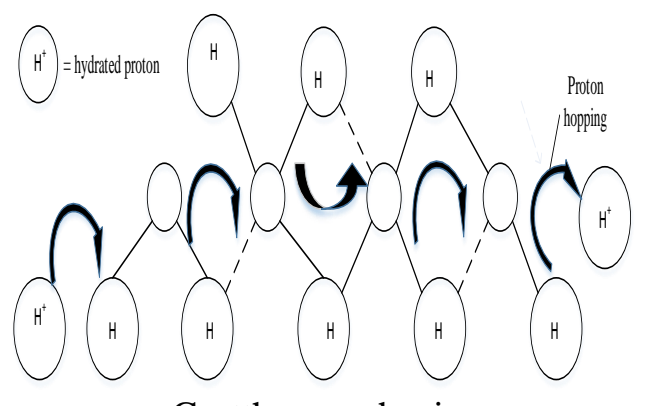

Grotthus mechanism

Figure 2 Mechanism of proton transport in membrane [21]

In free solution diffusion process, the hydrated proton diffuses through the water phase in response to the electrochemical difference and carried one or more molecules of water through the membrane and itself are transferred with them. This process involves mainly free water where proton is transported via interconnected pathway. The transferred protons from vehicular mechanism caused the existence of free volumes within polymeric chains which allow the transferring of the hydrated protons through the membrane.

The proton in Grotthus mechanism moves by a sequence of steps involving formation and breakage of hydrogen bonding of a series of water molecules. A proton hops from hydronium ion $\left(\mathrm{H}_{3} \mathrm{O}^{+}\right)$to a neighbouring $\mathrm{H}_{2} \mathrm{O}$ molecule and removes one of the protons to form hydrogen bonding with the adjacent proton. In addition, the original proton entering the membrane through the Grotthus mechanism is not the proton coming out of the membrane. This is because, only the charge of the proton is transported and not the proton itself [25-26]. This mechanism involves mainly bound water that facilitates the transport of proton by generation of continuous-like proton conductive pathway.

The proton transport mechanism in composite membranes is more complex process as it involves both the surface and chemical properties of the inorganic and organic phases. The proton conductivity of the composite membranes is depend on the amount of bulk water and the bulk proton concentrations that increased as a result of the addition of inorganic additives since the presence of inorganic fillers was expected to reduce the dehydration of membrane.

A smaller size and uniform distribution of inorganic fillers is expected to increase the ionic conductivity since more cations are mobile and available for conduction process [27]. Figure 3 illustrates the schematic diagram of proton transport mechanism in polymer-inorganic membranes. 


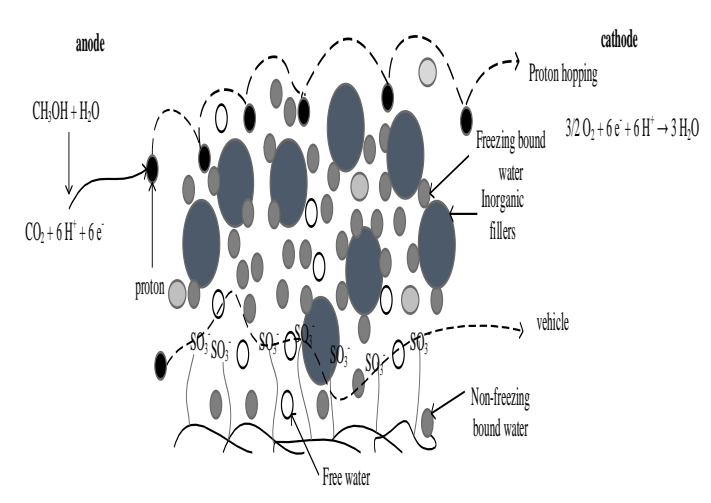

Figure 3 Transport mechanism in composite membrane

\subsection{TRANSPORT BEHAVIOUR OF WATER, METHANOL AND PROTON IN POLYMER- INORGANIC MEMBRANE}

In proton exchange membrane, the transport of protons and methanol can be described by the Nernst-Plank equations for the flux, $j_{i}$.

$$
-j i=D_{i}\left(\nabla c_{i}+z_{i} c_{i} F \frac{\nabla \Phi}{R T}\right)
$$

where $D_{i}$ is the diffusion coefficient, $c_{i}$ is the concentration, $z_{i}$ is the charge of species ' $i$ ', $F$ is Faraday's constant, $R$ is the gas constant, $T$ is the temperature, and $\Phi$ is the electrostatic potential.

For the conductance of protons (species " 1 "), $z_{1}$ is (+1) and the concentration $c_{1}$ is a constant, so for a membrane of thickness $l$

$$
-j_{1}=\left(\frac{D_{1} c_{1} F}{R T}\right) \frac{\nabla \Phi}{l}
$$

The results is more commonly written as a current density, $i$

$$
i=-F j_{1}=\sigma\left(\frac{\Delta \phi}{l}\right)
$$

where the conductivity, $\sigma$ is given by

$$
\sigma=D_{1} c_{1} F^{2} / R T
$$

For methanol species ("2"), $z_{2}$ is zero and

$$
j_{2}=D_{2} H_{2}\left(c_{20}-0\right) / l
$$

where $\mathrm{H}_{2}$ is a partition coefficient, the product $\mathrm{D}_{2} \mathrm{H}_{2}$ is the methanol permeability $P$, and $\left(c_{20}-0\right)$ is the concentration difference of methanol across the membrane. This equation is valid for fuel cells when electroosmosis does not contribute to the methanol flux.

In many membrane separations, selectivity is defined as the ratio of permeability. From the relationship between flux and permeability, $j=P \nabla c / l$, selectivity is defined as the ratio of fluxes to driving forces:

$$
\alpha=\frac{j_{1} / j_{2}}{\Delta c_{1} / \Delta c_{2}}
$$

For a methanol fuel cell membrane, the driving forces for protons and methanol are different. A new form of selectivity, termed electrochemical selectivity, $\beta$ is defined as:

$$
\beta=\frac{i / j_{2}}{\Delta \Phi / \Delta c_{2}}
$$

Therefore, by substituting the equation 3 and equation 5 into equation 7 yields:

$$
\beta=\frac{\sigma}{P}
$$

where $\sigma$ is the proton conductivity and $P$ is the methanol permeability. It is noted that the electrochemical selectivity is independent of membrane thickness.

According to Libby et al. [28], there was two potential scenarios for transport behavior in the composite membrane as shown in Figure 4. In case 1, proton conductivity in the continuum is much greater than in the 
spheres. As a result, protons move entirely in the continuous phase by travelled around and between the less conductive spheres. Because protons and methanol move by the same pathway through the continuum, the selectivity of the composite reduces to the selectivity of the continuum.

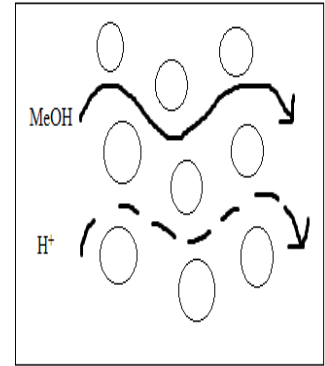

(a)

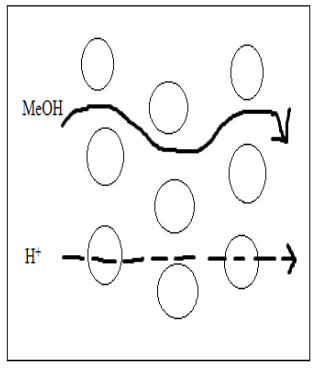

(b)
Figure 4 Potential transport scenario

(a) Case 1: $\sigma$ (continuum) $\gg \sigma$ (spheres),

(b) Case 2: $\sigma$ (spheres) $\gg \sigma$ (continuum) in a composite membrane

Case 2 represents the opposite scenarios of case 1 . As contrast to case 1 , the proton conductivity in the spheres is greater than in continuum. In this case, protons quickly moved through the spheres while methanol travels around and between them. The pathways separation for methanol and proton transport results in improved selectivity [29].

Various attempts have been made to develop membranes with high proton conductivity, low methanol permeability, at the same time not compromising other qualities such as good chemical and thermal stability, and cost. These include modification of the Nafion membranes, development of polymer/inorganic mineral acid composite membranes, partially fluorinated polymers and nonfluorinated polymers and their combinations [30]. The addition of inorganic fillers is believed to improve the proton conductivity and reduce the methanol permeability of the membranes. Various inorganic materials such as $\mathrm{SiO}_{2}, \mathrm{ZrO}_{2}$, heteropolyacids, phosphates, and Yzeolite had been successfully incorporated into polymer matrix to form composite membranes in order to improve the proton conductivity and control the methanol permeability[3133].

From previous research, it was found that a composite membranes consisting of $28 \mathrm{wt} \%$ tungstophosphoric acid (TPA) and $8 \mathrm{wt} \%$ zirconium oxide $\left(\mathrm{ZrO}_{2}\right)$ in an organic matrix of sulfonated polyetherketone (s-PEK) exhibited higher proton conductivity and lower methanol permeability than the unmodified s-PEK membrane [31].

In addition, Bello et al., proved that the proton exchange membrane for DMFC from SPEEK/TPA/MCM-41 composite membrane successfully exhibited higher proton conductivity than its native membrane [34]. These findings proved that the modification of polymeric membranes by addition of inorganic materials is indeed can improve both properties and hence resulted in higher selectivity as compared to their parent membrane.

The composite membrane was prepared by blending SPEEK with boron orthophosphate $\left(\mathrm{BPO}_{4}\right)$ for DMFC. The effects of the boron/phosphate $(\mathrm{B} / \mathrm{P})$ fraction of $\mathrm{BPO}_{4}$ and relative loading on methanol permeability and proton conductivity of the membrane are discussed. The composite membrane showed enhancement in proton conductivity with the incorporation of $\mathrm{BPO}_{4}$ particles into SPEEK until 20 wt \% and decreased suddenly after further $\mathrm{BPO}_{4}$ addition. The increase in proton conductivity of this composite membrane was probably associated with the acidic site of $\mathrm{BPO}_{4}$ and the presence of water in composite membranes. The incorporation of 
$\mathrm{BPO}_{4}$ with 0.8 B/P into SPEEK matrices recorded the highest water uptake, methanol permeability and proton conductivity, followed by $\mathrm{BPO}_{4}$ with $1.0 \mathrm{~B} / \mathrm{P}$ and the lowest is $1.2 \mathrm{~B} / \mathrm{P}$. These results were due to the uniform distribution of BPO4 in composite membrane and the pore size of $\mathrm{BPO}_{4}$. The methanol permeability of this composite membrane proportionally increased with $\mathrm{BPO}_{4}$ loading but still much lower than Nafion 117 membrane [35].

In another study, composite membranes based on sulfonated polyether ether ketone (SPEEK) and hydrated tin oxide $(\mathrm{SnO} 2 \cdot \mathrm{nH} 2 \mathrm{O})$ were also prepared and characterized. The membrane doped with 50wt $\%$ $\mathrm{SnO} 2 \cdot \mathrm{n}(\mathrm{H} 2 \mathrm{O})$ showed good proton transport characteristics, without any loss in conductivity due to the presence of a large amount of the inorganic phase. The presence of the oxide led to a decrease in the methanol permeability of the membrane, as well as to increase the membrane stability avoiding SPEEK degradation due to its water solubility. In fact, doping a SPEEK-based material with $50 \mathrm{wt} \%$ of hydrated tin oxide allowed the preparation of a proton-conducting membrane having low water swelling, low methanol permeability, large and stable proton conductivity, and exhibited good performance in a direct methanol fuel cell at $100{ }^{\circ} \mathrm{C}$ [36].

Ismail et al. [37] prepared new composite membranes using sulfonated polyether ether ketone (SPEEK) polymer and inorganic proton conducting fillers developed from tungstosilicic acids (SiWA) loaded on silica-aluminium oxide $\left(\mathrm{SiO}_{2}-\mathrm{Al}_{2} \mathrm{O}_{3}\right)$ composite. SiWA was fixed on stable structure (composite oxide) so that it became insoluble in water. It was found that the presence of inorganic proton conducting fillers led to both high water uptake and proton conductivity (maximum value 6.1 $\times 10-2$ Scm-1). The membranes which possessed higher DS, higher SiWA content and higher $\mathrm{SiO} 2$ content in $\mathrm{SiO}_{2}-\mathrm{Al}_{2} \mathrm{O}_{3}$ composite show higher water uptake and proton conductivity matrices due to the presence of Keggin structure owned by heteropolyacids, which contains high amount of water and still can take more water due to the specific Keggin properties. Water molecules also dissociate acid functionality and facilitate proton transport, so the water uptake is an important parameter in increasing the proton conductivity of the composite membranes [38]. Higher water uptakes generated a more solvated species which are needed for high proton conductivity. The water uptake of all membranes prepared was found to be higher than the Nafion 112 membrane. Low methanol permeability values were also recorded for the membranes when the sulfonation degree is higher. However, when the $\mathrm{SiO}_{2}$ composition in $\mathrm{SiO}_{2}-\mathrm{Al}_{2} \mathrm{O}_{3}$ composite is increased, the methanol permeability also increased but the value was still lower than Nafion 112.

\subsection{PREDICTIVE MODELS FOR POLYMER-INORGANIC MEMBRANE PERFORMANCE}

The study on the need of a model to describe permeability in composite membrane is always based on the permeability of the penetrants through matrix phase and filler phase, and the amount of the filler added. Therefore, many researchers reported their modelling study on the influence of solid fillers dispersion in a polymeric matrix on permeability has been studied by researchers [14]. The commonly used models for predicting the permeability of the solute through a polymer-inorganic composite 
membrane are Maxwell and Bruggeman models [39-41]. The summary of predictive models for polymer-inorganic membrane performances is shown in Table 1.

Maxwell model is developed to analyse the electrical conductivity of heterogenous composites [42]. This model is often used to evaluate the permeability in polymer-inorganic nanocomposite membranes. Barrer et $a l$. stated that the membrane filled with impermeable spherical particles is reduced to equation below:

$$
P_{e f f}=P_{C}\left(\frac{1-\varphi}{1+0.5 \varphi}\right)
$$

where $P_{\text {eff }}$ is the permeability of the composite membrane, $P_{C}$ is the permeability of the gas in the pure polymer matrix and the $\varphi$ is the volume fraction of nanofiller nanoparticles .

This model partly explains the gas permeability loss in some nanocomposite membranes, especially in polymer-fullerene membranes [43]. The effective permeability decreases upon increasing the volume fraction of impermeable nanoparticles and is believed to be the result of the reduction in membrane solubility due to the decrease to polymer content, and of diffusivity reduction due to the increase of the penetrant diffusion pathway length [44]. Maxwell equation was used in analysing a series of polysulfone (PS)/ poly (dimethylsiloxane) (PDMS) block copolymers to interpret $\mathrm{O}_{2}$ permeability data. The $\mathrm{O}_{2}$ permeability of the unfilled poly (dimethylsiloxane) determined by extrapolation, was found to be $7.2 \times 10^{-8} \quad(\mathrm{~cm} 3 / \mathrm{cm} \mathrm{s}$ 10Torr), while, the $\mathrm{O}_{2}$ permeability in (PS) was $1.3 \times 10^{-10}\left(\mathrm{~cm}^{3} / \mathrm{cm} \mathrm{s} 10\right.$ Torr $)$. From the study, the experimental and predicted data shows well correlations with Maxwell model [45].
Table 1 Predictive models for membrane performance

\begin{tabular}{|c|c|c|}
\hline $\begin{array}{c}\text { Predictive } \\
\text { models }\end{array}$ & Characteristics & Limitation \\
\hline $\begin{array}{l}\text { Maxwell } \\
\text { model }\end{array}$ & $\begin{array}{l}\text { Originally } \\
\text { developed for } \\
\text { electrical } \\
\text { conductivity of } \\
\text { particulate } \\
\text { composites; } \\
\text { valid for low to } \\
\text { moderate } \\
\text { values of filler } \\
\text { concentration } \\
\varphi(0<\varphi<0.2) ; \text { it } \\
\text { does not take } \\
\text { into account the } \\
\text { packing limit of } \\
\text { particles }(\varphi m) \text {. }\end{array}$ & $\begin{array}{l}\text {-an explicit } \\
\text { relation, } \\
\text { easy to solve } \\
\text { for } \\
\text { permeability. } \\
\text { - The effects } \\
\text { of particle } \\
\text { size } \\
\text { distribution, } \\
\text { particle } \\
\text { shape, and } \\
\text { aggregation } \\
\text { of particles } \\
\text { are not } \\
\text { considered. }\end{array}$ \\
\hline $\begin{array}{l}\text { Bruggeman } \\
\text { model }\end{array}$ & $\begin{array}{l}\text { Originally } \\
\text { developed for } \\
\text { dielectric } \\
\text { constant of } \\
\text { particulate } \\
\text { composites; this } \\
\text { model covers a } \\
\text { broader range } \\
\text { of } \varphi \text { compared } \\
\text { with the } \\
\text { Maxwell } \\
\text { model. }\end{array}$ & $\begin{array}{l}\text {-does not } \\
\text { take into } \\
\text { account the } \\
\text { packing limit } \\
\text { of particles } \\
(\varphi m) \text {. } \\
\text {-The effects } \\
\text { of particle } \\
\text { size } \\
\text { distribution, } \\
\text { particle } \\
\text { shape, and } \\
\text { aggregation } \\
\text { of particles } \\
\text { are ignored. } \\
\text {-an implicit } \\
\text { relation that } \\
\text { needs to be } \\
\text { solved } \\
\text { numerically } \\
\text { for } \\
\text { permeability. }\end{array}$ \\
\hline
\end{tabular}

However, Maxwell equation is only applicable to dispersions with low filler content less than 20wt.\%. This is due to the assumption that the flux pattern around a particle is not disturbed by the presence of other filler particles since the model neglected the interactions between the fillers and the polymer chains, and the fillers and the penetrants [43]. In most composite membranes, these interactions are strong, and significantly change the 
diffusivity and solubility of the penetrants. Therefore, the Maxwell equation does not included the distribution of the filler impact in the matrix [46]. The composite membrane containing PVA and zeolite for DMFC application was prepared by Libby et $a l$. and the effect of addition of inorganic additives into the polymer matrix was studied. The results showed that the PVA/modernite composite membrane containing $50 \%$ mordenite by volume exhibit improvement in selectivity compared to Nafion. The experimental data shows a well correlation by Maxwell's theory for conducting spheres in a continuum. Therefore, it can be concluded that the model can be a reasonable guide to selectivity changes in the synthesized membranes [29].

In addition, Mahajan et al. [40] prepared membranes containing 4A zeolite in polymers such as polyvinyl acetate (PVAc), Ultems polyetherimide (PEI), Matrimids polyimide (PI) among others and predicted the permeability by using Maxwell model. They found a good correlation with the Maxwell model. However, there are the differences in permeability between the model prediction and experimental results in the membranes at high loadings of zeolites in the polymer matrix, in which the $\mathrm{O}_{2} / \mathrm{N}_{2}$ selectivity for the membranes reached almost twice that of pure polymer membranes [47]. This shows that the Maxwell model only assumed uniform polymer permeability throughout the matrix. Thus, the effects of particle size distribution, particle shape and aggregation of particles are not considered.

Another model which related to the transport properties in the composite membrane is Bruggeman model. This model originally developed for the study of electric constant in particulate composites. This model incorporates an integration technique to approximate the effect of adding particles to a dilute suspension [48]. In this model, the effect of adding additional particles to a dilute suspension for a random dispersion was considered. The Bruggeman equation for a random dispersion of spherical particles is:

$\left[\frac{\left(\frac{P_{e f f}}{P_{C}}\right)-\left(\frac{P_{d}}{P_{C}}\right)}{1-\left(\frac{P_{d}}{P_{C}}\right)}\right]\left(\frac{P_{e f f}}{P_{C}}\right)^{-\frac{1}{3}}=1-\varphi_{d}$

where $P_{d}$ is the permeability of gas in dispersed phase and $\varphi_{d}$ is the volume fraction of the second phase in the composite membrane. In general, the Bruggeman Model was observed to consistently predict both higher permeabilities and permselectivities than the Maxwell Model. However, this model contains an implicit function that needs to be solved numerically.

A series of works on the comparison between the experimental permeation data and the predicted values estimated by the Bruggeman and original Maxwell models for $\mathrm{CO}_{2} / \mathrm{CH}_{4}$ and $\mathrm{O}_{2} / \mathrm{N}_{2}$ separations has been conducted by $V u$ et al. [39]. Mixed matrix membranes CMS/polymer were synthesized via a flat-sheet solution casting method using carbon molecular sieves (CMS) dispersed within two different polymer matrices: Matrimid 5218 and Ultem 1000. The loading of CMS particles was varied from 10 to 50 vol \%. For CMS- based MMMs prepared with Ultem 1000 polymer, the Bruggeman model predicts better permeability and permselectivity than the original Maxwell model. This was attributed to the fact that the Bruggeman model appears to account for disrupted flow patterns around the CMS particles under high loading condition.

Bouma et al. reported an investigation on the influence of solid 
fillers dispersed in a polymer matrix on permeability. The MMMs consist of polyvinylidenefluoride-hexafluoropro pene (PVDF) with nematic liquid crystalline mixture E7 was prepared via the solvent-casting method with ethyl acetate as a solvent. The loading of E7 was varied between 0.5 and 25 wt $\%$.

Both the original Maxwell and Bruggeman models were applied to predict the $\mathrm{O}_{2}$ permeability of these coPVDF/E7 MMMs. From the results, it was concluded that the Maxwell equation is an analytically correct method applicable at low filler loadings, while the Bruggeman model much better describes the membrane performance of MMM at higher filler concentration [46].

In addition, Keskin and Sholl reported a comparative molecular simulation study of the gas mixture separation through a series of IRMOF1/Matrimid MMMs by applying both the original Maxwell and Bruggeman models. IRMOF-1 is a metal organic framework (MOF) material having the MOF-5 structure.

Using experimental permeation data of several gas mixtures such as $\mathrm{H}_{2} / \mathrm{CH}_{4}, \mathrm{CO}_{2} / \mathrm{CH}_{4}, \mathrm{CH}_{4} / \mathrm{N}_{2}, \mathrm{H}_{2} / \mathrm{CO}_{2}$, and $\mathrm{H}_{2} / \mathrm{N}_{2}$ it showed that a slight agreement between predictions by these two models and experimental data. For example, both model predictions are slightly overestimating the experimental permeabilities of $\mathrm{CH}_{4}, \mathrm{~N}_{2}, \mathrm{CO}_{2}$, and $\mathrm{H}_{2}$ gases. The Bruggeman model predicted higher permeability values than the original Maxwell model, especially at high MOF loadings. In addition, the ideal selectivities of gas pairs calculated from the original Maxwell model are slightly lower than the experimental value.

\subsection{CONCLUSION}

The modification of PEM for DMFC application have improved the properties of the membrane such as high proton conductivity, low methanol permeability, high selectivity, good hydrophilicity, mechanical strength, and thermal and chemical stability. The presence of dispersed inorganic fillers has been useful for the improvement of membrane performances ranging from gas separation and pervaporation to nanofiltration, ultrafiltration and fuel cell. The models of Maxwell and Bruggeman are currently the most widely accepted for predicting gas permeability through polymerinorganic composite membranes. Each model has been established for specific conditions as per discussed and, consequently, there is no existing model valid for a wide range of applications including fuel cell. Therefore, more experimental information regarding predictive models for predicting the performance of the resulting membrane is needed.

\section{ACKNOWLEDGEMENT}

The author (Nik Nurdhiya) would like to express gratitude to the Ministry of Science, Technology and Innovation (MOSTI) Malaysia for the grants with vote number of R.J130000.7809.4F592,

Q.J130000.2509.05H52 and R.J130000.7942.4S507 for the financial support and also to the research management centre (RMC), UTM for supporting related research management activities. 


\section{REFERENCES}

[1] G. Acres. 2001. Recent advances in fuel cell technology and its applications. J. Power Sources. 100: 60-66.

[2] A. Boudghene Stambouli and E. Traversa. 2002. Fuel cells, an alternative to standard sources of energy. Renew. Sustain. Energy Rev. 6:295-304.

[3] A. Demirbas. 2008. Direct Use of Methanol in Fuel Cells. Energy Sources, Part A Recover. Util. Environ. Eff. 30:529-535.

[4] V. S. Silva, J. Schirmer, R. Reissner, B. Ruffmann, H. Silva, A. Mendes, L. M. Madeira, S. P. Nunes, and Y. A. Gallego. 2005. Proton electrolyte membrane properties and direct methanol fuel cell performance. J. Power Sources. 140:34-40.

[5] Z. Gaowen and Z. Zhentao.2005. Organic/inorganic composite membranes for application in DMFC. J. Memb. Sci. 261:107113.

[6] T. Yang and C. Liu. 2011. SPEEK/sulfonated cyclodextrin blend membranes for direct methanol fuel cell. Int. J. Hydrogen Energy. 36:56665674.

[7] A. S. Aricò, V. Baglio, and V. Antonucci. 2009. Direct Methanol Fuel Cells: History, Status and Perspectives. In $\mathrm{H}$. Liu and J. Zhang (Eds.). Electrocatalysis of Direct Methanol Fuel Cells. Weinhem: Verlag $\mathrm{GmbH} \& \mathrm{Co}$.

[8] B. L. Garcia and J. W. Weidner. 1990. Review of Direct Methanol Fuel Cells. J. Power Sources. 5: 229-284.

[9] C. Karthikeyan, S. Nunes, L. Prado, M. Ponce, H. Silva, B. Ruffmann, and K. Schulte. 2005. Polymer nanocomposite membranes for DMFC application. J. Memb. Sci. 254:139-146.

[10] R. Gosalawit, S. Chirachanchai, S. Shishatskiy, and S. P. Nunes. 2008. Sulfonated montmorillonite/sulfonated poly(ether ether ketone) (SMMT/SPEEK) nanocomposite membrane for direct methanol fuel cells (DMFCs). J. Memb. Sci. 323:337-346.

[11] M. N. A. M. Norddin, A. F. Ismail, D. Rana, T. Matsuura, A. Mustafa, and A. TabeMohammadi.2008.Characterizati on and performance of proton exchange membranes for direct methanol fuel cell: Blending of sulfonated poly(ether ether ketone) with charged surface modifying macromolecule. J. Memb. Sci.. 323:404-413.

[12] M. A. Hickner. 2003. Transport and Structure in Fuel Cell Proton Exchange Membranes Transport and Structure in Fuel Cell Proton Exchange Membranes. Virginia Polytechnic Institute and State University. PhD. Thesis.

[13] B. P. Tripathi and V. K. Shahi. 2011.Organic-inorganic nanocomposite polymer electrolyte membranes for fuel cell applications. Prog. Polym. Sci. 36:945-979.

[14] S. P. Nunes, B. Ruffmann, E. Rikowski, S. Vetter, and K. Richau. 2002. Inorganic Modification of Proton Conductive Polymer Membranes for Direct Methanol Fuel Cell. J. Memb. Sci. 203:215-225.

[15] J. Wootthikanokkhan and N. Seeponkai. 2006. Methanol permeability and properties of DMFC membranes based on sulfonated PEEK/PVDF blends. J. Appl. Polym. Sci. 102:59415947. 
[16] S. Byun, Y. Jeong, J. Park, S. Kim, H. Ha, and W. Kim. 2006. Effect of solvent and crystal size on the selectivity of ZSM5/Nafion composite membranes fabricated by solution-casting method. Solid State Ionics. 177:3233-3243.

[17] Y. Kim, J. S. Lee, C. H. Rhee, H. K. Kim, and H. Chang, 2006. Montmorillonite functionalized with perfluorinated sulfonic acid for proton-conducting organicinorganic composite membranes. J. Power Sources, 162: 180-185.

[18] Y. F. Lin, C. Y. Yen, C. H. Hung, Y. H. Hsiao, and C. C. M. Ma. 2007. A novel composite membranes based on sulfonated montmorillonite modified Nafion for DMFCs. J. Power Sources. 168:162-166.

[19] M. Helen, B. Viswanathan, and S. Murthy. 2007. Synthesis and characterization of composite membranes based on $\alpha$ zirconium phosphate and silicotungstic acid. J. Memb. Sci. 292: 98-105.

[20] J. Wee. 2007. Applications of proton exchange membrane fuel cell systems. Renew. Sustain. Energy Rev., 11:1720-1738.

[21] J. G. Wijmans and R. W. Baker. 1995. The solution-diffusion model: a review. J. Memb. Sci. 107: 1-21.

[22] V. C. Souza and M. G. N. Quadri. 2013. Organic-Inorganic Hybrid Membranes In Separation Processes: A 10-Year Review. Brazilian J. Chem. Eng. 30: 683700.

[23] A. L. Zydney. 2011. High Performance Ultrafiltration Membranes: Pore Geometry and Charge Effects. Inorganic, Polym. Compos. Membr. Struct. Funct. Other Correl. 14: 333.
[24] T. Okada, M. Yoshikawa, and T. Matsuura. 1991. A study on the pervaporation of ethanol/water mixtures on the basis of pore flow model. J. Memb. Sci. 59: 151-168.

[25] W. Jiang. 1999. Preparation and characterization of pore-filled cation-exchange membranes. McMaster University, Hamilton, Ontario. PhD. Thesis.

[26] S. H. Park, J. S. Park, S. D. Yim, Y. M. Lee, and C. S. Kim. 2008. Preparation of organic/inorganic composite membranes using two types of polymer matrix via a sol-gel process. J. Power Sources. 181: 259-266.

[27] H. Kim and H. Chang. 2007. Organic/inorganic hybrid membranes for direct methanol fuel cells. J. Memb. Sci. 288: 188-194.

[28] B. Libby. 2001. Improving selectivity in methanol fuel cell membranes: A study of a polymer-zeolite composite membrane. University of Minnesota. PhD. Thesis.

[29] B. Libby, W. H. Smyrl, and E. L. Cussler. 2003. Polymer-zeolite composite membranes for direct methanol fuel cells. AIChE J. 49: 991-1001.

[30] S. M. Zaidi, S. Mikhailenko, G. Robertson, M. Guiver, and S. Kaliaguine. 2000. Proton conducting composite membranes from polyether ether ketone and heteropolyacids for fuel cell applications. J. Memb. Sci. 173: 17-34.

[31] M. Ponce, L. Prado, B. Ruffmann, K. Richau, R. Mohr, and S. Nunes. 2003. Reduction of methanol permeability in polyetherketone-heteropolyacid membranes. J. Memb. Sci. 217: $5-15$. 
[32] B. Ruffmann. 2003. Organic/inorganic composite membranes for application in DMFC. Solid State Ionics. 162: 269-275.

[33] M. M. Hasani-Sadrabadi, E. Dashtimoghadam, K. Sarikhani, F. S. Majedi, and G. Khanbabaei. $2010 . \quad$ Electrochemical investigation of sulfonated poly(ether ether ketone)/clay nanocomposite membranes for moderate temperature fuel cell applications. J. Power Sources. 195: 2450-2456.

[34] M. Bello, S. M. J. Zaidi, and S. U. Rahman. 2008. Proton and methanol transport behavior of SPEEK/TPA/MCM-41

composite membranes for fuel cell application. J. Memb. Sci. 322:218-224.

[35] M. H. D. Othman, A. F. Ismail, and A. Mustafa. 2007. Proton conducting composite membrane from sulfonated poly(ether ether ketone) and boron orthophosphate for direct methanol fuel cell application. J. Memb. Sci. 299: 156-165.

[36] B. Mecheri, A. D'Epifanio, E. Traversa, and S. Licoccia. 2008. Sulfonated polyether ether ketone and hydrated tin oxide proton conducting composites for direct methanol fuel cell applications. J. Power Sources, 178: 554-560.

[37] A. F. Ismail, N. H. Othman, and A. Mustafa. 2009. Sulfonated polyether ether ketone composite membrane using tungstosilicic acid supported on silicaaluminium oxide for direct methanol fuel cell (DMFC). J. Memb. Sci. 329: 18-29.

[38] P. Xing, G. P. Robertson, M. D. Guiver, S. D. Mikhailenko, K. Wang, and S. Kaliaguine. 2004. Synthesis and characterization of sulfonated poly(ether ether ketone) for proton exchange membranes. J. Memb. Sci., 229: 95-106.

[39] D. Q. Vu, W. J. Koros, and S. J. Miller. 2003. Mixed matrix membranes using carbon molecular sieves. J. Memb. Sci. 211: 335-348.

[40] T. T. Moore, R. Mahajan, D. Q. $\mathrm{Vu}$, and W. J. Koros. 2004. Hybrid membrane materials comprising organic polymers with rigid dispersed phases. AIChE J. 50: 311-321.

[41] R. Pal. 2008. Permeation models for mixed matrix membranes. J. Colloid Interface Sci. 317: 1918.

[42] J. R. Kalnin and E. Kotomin. 1998. Modified Maxwell-Garnett equation for the effective transport coefficients in inhomogeneous media. J. Phys. A. Math. Gen. 31: 7227-7234.

[43] T. S. Chung, L. Y. Jiang, Y. Li, and S. Kulprathipanja. 2007. Mixed matrix membranes (MMMs) comprising organic polymers with dispersed inorganic fillers for gas separation. Prog. Polym. Sci. 32: 483-507.

[44] P. Bernardo, E. Drioli, and G. Golemme. 2009. Membrane Gas Separation: A Review/State of the Art. Ind. Eng. Chem. Res. 48: 4638-4663.

[45] L. M.Robeson, A. Noshay, M. Matzner, and C. N. Merriam. 1972. Physical Property Characteristics of Polysufone/Poly(dimethylsiloxan ) block copolymers. D. Ange. Makro. Chem. 30: 47-62.

[46] R. H. B. Bouma, A. Checchetti, G. Chidichimo, and E. Drioli. 1997. Permeation through a heterogeneous membrane: the 
Effect Of The Dispersed Phase. J. Memb. Sci. 128: 141-149.

[47] K. A. Mauritz and R. B. Moore. 2004. State Of Understanding Of Nafion. Chem. Rev. 104: 453585.
[48] S. Saufi and A. Ismail. 2004. Fabrication Of Carbon Membranes For Gas Separation-A Review. Carbon. 42: 241259. 